\title{
Scale and forms of domestic violence against schoolchildren in rural, rural-urban and urban areas
}

\author{
Albert Terelak ${ }^{1, A-F} \oplus$, Sebastian Kołodziejczak ${ }^{1, A-F} \oplus$, Marek Bulsa ${ }^{1, D-F \oplus}$ \\ ${ }^{1}$ University of Szczecin, Poland \\ A - Research concept and design, B - Collection and/or assembly of data, C - Data analysis and interpretation, \\ $D$ - Writing the article, E - Critical revision of the article, F - Final approval of article
}

Terelak A, Kołodziejczak S, Bulsa M. Scale and forms of domestic violence against schoolchildren in rural, rural-urban and urban areas. Ann Agric Environ Med. 2019; 26(4): 572-578. doi: 10.26444/aaem/103871

\begin{abstract}
Introduction. In 2017, the third cyclical study on the scale of domestic violence against schoolchildren and youth in one of the rural communes of the Western Pomerania (Poland) was carried out. The study took into account five forms of violence: mental, physical, neglect, economic and sexual. The previous two editions of the study covered urban-rural (2016) and urban communities (2015).

Materials and method. The research concept was implemented by means of the representative research method, using an auditing questionnaire interview technique, based on a research tool developed on the basis of a number of previous qualitative research and quantitative tests to measure the social scale of domestic violence.

Results. Domestic violence against minors reaches $48.2 \%$ in the rural area under study, $51.8 \%$ in the urban-rural area and $65.5 \%$ in the urban area. In all types of areas, the most frequent form of violence was psychological violence, it affects $42.4 \%$ of children in rural communitys, $51.3 \%$ in urban-rural and $60.5 \%$ in urban municipalities. In reference to other, less frequent forms of violence, there was also a difference in scale according to the area type.

Conclusions. The incidence of individual forms of domestic violence varied depending on the type of area: Psychological violence: rural areas - 42.4\%, urban-rural - 51.3\%, urban areas - 60.5\%; Neglect: rural areas - 21.1\%, urban-rural - $13.5 \%$, urban areas - 22.3\%; Physical violence: rural areas - 17.1\%, urban-rural - 20.7\%, urban areas - 29.4\%; Economic violence: rural areas $-12.6 \%$, urban-rural - 19.2\%, urban areas $-29.3 \%$; Sexual violence: rural areas - 3.2\%, urban-rural - 3.6\%, urban areas $-8.1 \%$.
\end{abstract}

\section{Key words}

domestic violence, child abuse, adolescents, rural areas, physical violence, psychological violence, sexual violence, physical neglect, psychological neglect, family violence.

\section{INTRODUCTION}

In principle, the existing definitions refer to domestic violence as specific acts or omissions when these are the result of social expectations about the role of the perpetrator towards the victim. These definitions also indicate that the act of violence is directed towards the rights or goods in the possession of the victim (usually life or health, in physical and/or mental terms), resulting in harm and suffering. In most cases, violence is defined by reference to a variety of criteria relating mainly to the extent of the harm suffered by the victim, the consequences of violence in different spheres of life, violation of the law and social norms, and the dynamics of the violence suffered by the perpetrators' family members $[1,2]$.

Domestic violence is often defined with reference to existing definitions used by formal institutions, e.g. Home Office [3] or World Health Organization [4]. In the presented research results, the interpretation of domestic violence is based on the provisions of the Polish Act on Counteracting Domestic Violence of 2005, which defines domestic violence as

Address for correspondence: Sebastian Kołodziejczak, University of Szczecin, Poland

e-mail: seb.kolodziejczak@o2.pl

Received: 14.12.2018; accepted: 10.02.2019; first published:01.03.2019
(...) a single or repeated intentional act or omission infringing the rights or personal property of persons [...], in particular exposing these persons to the danger of loss of life, health, violating their dignity, physical integrity, freedom, including sexual freedom, causing damage to their physical or mental health, as well as causing suffering and moral harm... [5].

As the formal system for preventing violence and abuse against children in Poland is developing [6], the use of that definition is most relevant.

In the presented study, the following forms of domestic violence were taken into consideration: psychological, physical, economic violence, sexual assault and neglect, generally understood as a harmful failure to fulfill the obligation resulting from the social role played by the perpetrator towards the victim [7].

\section{OBJECTIVE}

Research on domestic violence aimed at the differences between types of area are rarely realized; however, the variable of the place of residence may be significant in the context of the scale of occurrence of the phenomenon [89, $10,11]$. 
The presented research focused on determining the scale of domestic violence against schoolchildren and youths in the different types of communities (rural, urban-rural, urban) of West Pomerania, Poland. Five forms of violence (psychological, physical, economic violence, neglect, sexual assault) were taken into account. The research questionnaire was elaborated to measure the social scale of particular forms of domestic violence in their personal experience, and in their observations or indirect experience.

Such a broad view of the phenomenon made it possible to gain knowledge of a deeper nature (referring not only to the scale of domestic violence against schoolchildren and youths, but also to the scale of complexity of the problem of violence in families affected), and also of a cumulative nature due to the fact that the respondents' reports on the wrongs suffered by members of their families from other household members or close or further relatives, broaden the picture of the phenomenon under study. The adopted perspective also helped to discover risk factors contributing to domestic violence against children.

\section{MATERIALS AND METHOD}

The adopted research concept was realized with using the audit questionnaire interview technique, based on research tools to measure the social scale of domestic violence suffered by schoolchildren. The research was conducted among the last class of pupils of primary schools and secondary schools students in three communities of the West Pommeranian Province, Poland:

- in the rural community (2017), on a representative sample of 380 community schoolchildren and youths - empirical value of the compliance test $\chi 2=1.884$ to a critical value of 5.991 - for $\mathrm{df}=2$ and $\alpha=0.05$ (the community consists of 45 villages, population app. 8,000);

- in the urban-rural community (2016), on a representative sample of 193 community schoolchildren and youthS empirical value of the compliance test $\chi 2=1.669$ to a critical value of $5.991-$ for $\mathrm{df}=2$ and $\alpha=0.05$ (the community consists of a town and three villages, population - approx. $6,500)$;

- in the urban community (2015) on a representative sample of 779 community schoolchildren and youthS - empirical value of the compliance test $\chi 2=3.498$ to a critical value of 7.815 - for $\mathrm{df}=3$ and $\alpha=0.05$ (the community consists of one city, population approx. 41,000).

Because of the extremely complex and difficult issues, as well as the need to ensure a sense of security, intimacy and anonymity of the survey participants, efforts were made (in cooperation with the school management and staff) to organize the data collection process in such a way that during the audit interview:

1) there was only one pupil sitting on a school bench;

2) respondents received questionnaires with envelopes and were instructed to seal the envelope after answering the questionnaire to ensure complete anonymity, and ensuring that no one but the researchers could have access to the content of the questionnaire;

3) interviewees were informed that the survey would be used to design family support programmes, so it was important that the answers were honest and truthful (they were by no means compelled to give the answers - they had the right to put the unfilled questionnaire in the envelope);

4) interviewers informed participants where to seek help in their school or neighborhood, if necessary. That precaution was taken to avoid the risk of secondary victimization.

During the audit interview, respondents were asked to indicate whether, during the six months preceding the survey and possibly in the past, they experienced from their family members specific behaviours representing various forms of violence expressed by means of indicators adopted on the basis of previous qualitative surveys (Individual In-depth Interviews and Focus Group Interviews), as well as quantitative tests presented in the following table.

Table 1. Indicators of domestic violence used in the study

\begin{tabular}{|c|c|}
\hline $\begin{array}{l}\text { Form of } \\
\text { domestic } \\
\text { violence }\end{array}$ & $\begin{array}{l}\text { Indicators used in the questionnaire } \\
\text { Indicators adopted in the course of operationalization (or during the } \\
\text { study) }\end{array}$ \\
\hline $\begin{array}{l}\text { Psychological } \\
\text { violence }\end{array}$ & $\begin{array}{l}\text { - harmful criticism, humiliation } \\
\text { - forced submission by shouting* } \\
\text { - stubborn mockery / derision / ridicule in the eyes of others } \\
\text { - blaming for even minor mistakes, failure / multiple blaming for } \\
\text { the perpetrator's own mistakes } \\
\text { - offensive comments, vulgar expressions towards the victim; }\end{array}$ \\
\hline $\begin{array}{l}\text { Physical } \\
\text { violence }\end{array}$ & $\begin{array}{l}\text { - jerking and / or poking or pushing, etc., e.g. to hasten the } \\
\text { victim* } \\
\text { - single or repeated slamming with a hand and / or kicking, etc. } \\
\text { - beating with a tool that leaves no distinct, permanent marks on } \\
\text { the body, } \\
\text { - beating that leaves distinct, visible bruises or wounds; }\end{array}$ \\
\hline Neglect & $\begin{array}{l}\text { - lack of concern for problems and / or ignoring feelings / } \\
\text { trivialising emotions* } \\
\text { - unjustified deprivation / restriction of food, drink, sleep } \\
\text { - disregard for ill-health or neglecting care in case of illness } \\
\text { - failure to provide necessary medical assistance }\end{array}$ \\
\hline $\begin{array}{l}\text { Economic } \\
\text { violence }\end{array}$ & $\begin{array}{l}\text { - disproportionate, persistent control of expenditure } \\
\text { - refusal to pay / provide for reasonable needs } \\
\text { - deprivation of Money / income }\end{array}$ \\
\hline $\begin{array}{l}\text { Sexual } \\
\text { assault }\end{array}$ & $\begin{array}{l}\text { - unpleasant, unwanted sexual remarks about the victim } \\
\text { - "groping", inappropriate touching parts o the body } \\
\text { - sexual abuse - inappropriate, unacceptable sexual behavior } \\
\text { towards the victim }\end{array}$ \\
\hline
\end{tabular}

studies conducted in 2015 and 2016 did not include this indicator

Source: own elaboration

\section{RESULTS}

The results of the collected empirical material allowed the conclusion that $48.2 \%$ of schoolchildren and youths participating in the study in rural areas, $51.8 \%$ in urbanrural areas, and $65.5 \%$ in urban areas, had suffered domestic violence. Most frequently, they experienced a single form of violence (rural areas - 19.5\%, rural-urban areas - $22.3 \%$, urban areas $-23.7 \%$ ). The proportion of children declaring that they had been victims of a greater number of forms of violence is gradually decreasing, with the percentage of those subject to all five forms of violence ranged from $0.5 \%$ in a rural community to $1 \%$ in an urban-rural community, to $3.3 \%$ in an urban community. If it is assumed that the declared experience of three or more types of domestic violence indicated the existence of an atmosphere of condensed violence in the family, and depending on the area, this situation affects from $13.6 \%$ in the rural community 
to $11.9 \%$ in the urban-rural community to $23.8 \%$ of survey participants living in an urban community.

It seems that this part should be treated as a category requiring special attention from the system of formal social control (Interdisciplinary Team for Counteracting Domestic Violence and individual institutions whose members are part of it) $[12,13]$. Co-occurrence of three or more forms of violence in the family environment seems to reveal cumulative symptoms of pathological family life, putting at risk the health, and even the lives victims of domestic violence.

The proportions in the sample of schoolchildren and youths from the described types of communities who have experienced particular forms of domestic violence are presented in the figure below.

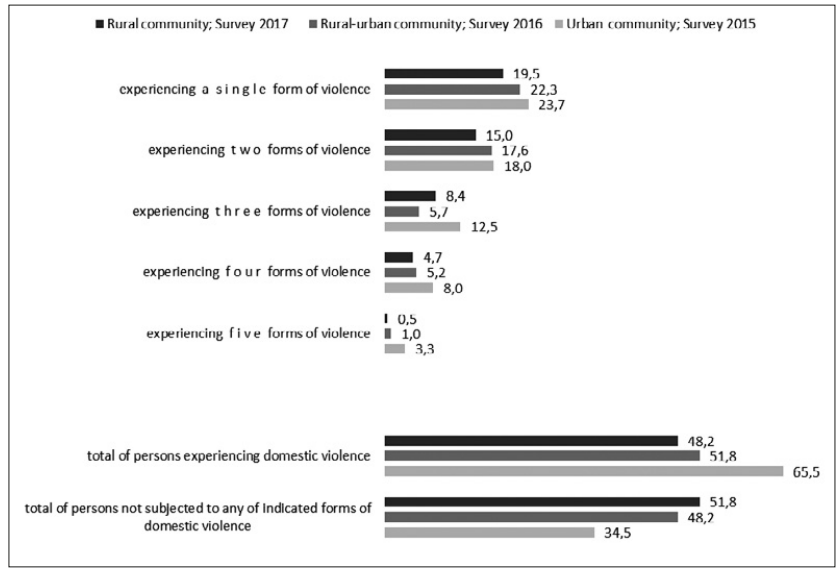

Figure 1. Number of forms of domestic violence suffered by schoolchildren and youths in rural, urban-rural and urban communities.

Data expressed in \%; n survey $2017=380=100 \%$; n survey $2016=193=100 \%$; survey $2015=779=100 \%$

Source: own study

The above data triggers reflection on the differences in the incidence of domestic violence by area of residence. While the experience of individual forms of violence (one or two) does not show significant differences between rural and urban areas, acts of more complex domestic violence against children and young people (three or more forms), as well as the ratio between those experiencing violence and those not experiencing any form of violence, raises some questions and encourages further research in order to examine the hypothesis that scale of domestic violence in cities is bigger than in rural areas.

A more detailed perspective on the structure of domestic violence is provided by Figure 2, which shows the intensity of each form of domestic violence (neglect, mental, physical, economic violence and sexual assault) through the distribution of the numbers of acts of violence (indices) experienced within each category, compared with the distribution of respondents experiencing and not experiencing the forms of violence under investigation.

In the experience of the participants of all three surveys, psychological violence was predominant; in rural areas (survey of 2017) and declared by $42.4 \%$ of the respondents. The scale of psychological violence was confirmed by the fact that while the proportion of other forms of domestic violence did not exceed a quarter or even a fifth of schoolchildren and youth, the proportion of acts of psychological violence oscillated around $50 \%$. This is evidenced by the results

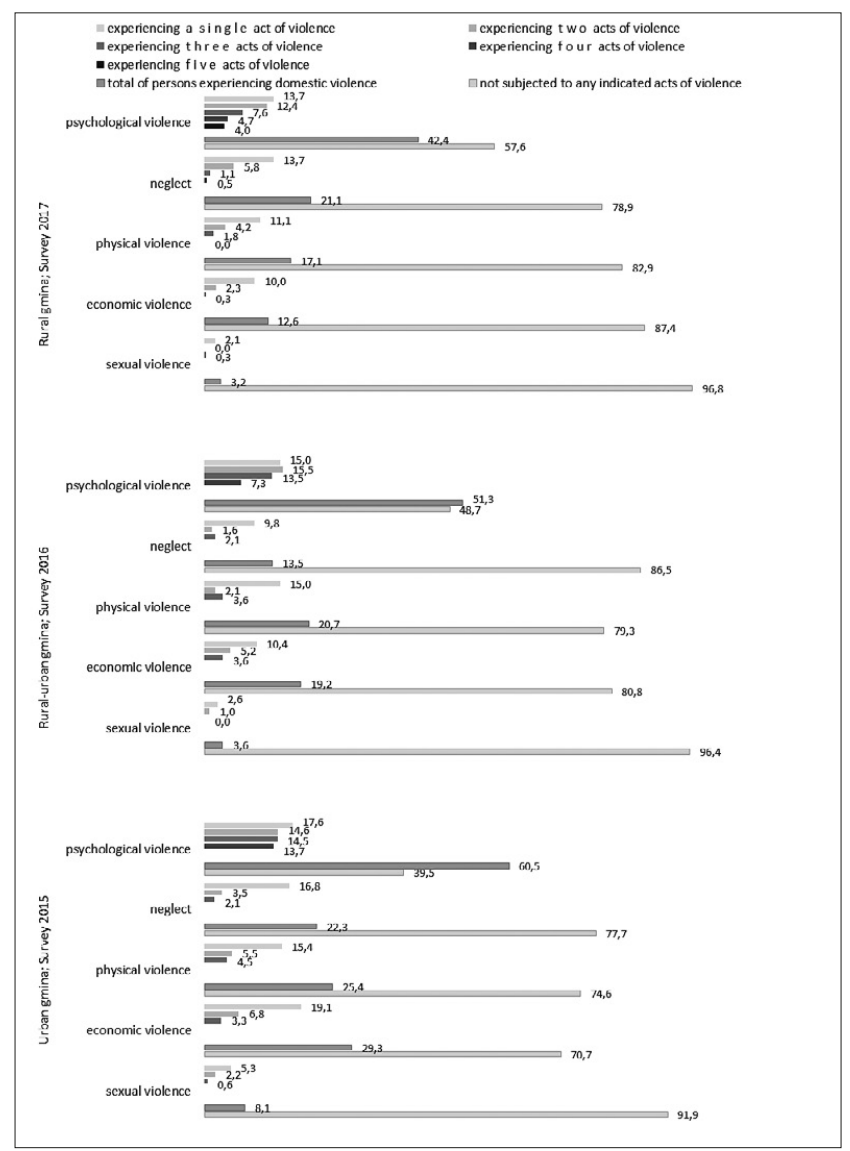

Figure 2. Scale of the 5 forms of domestic violence experienced by schoolchildren and youths in 3 types of community: rural, urban-rural and urban, according to conducted surveys

Data expressed in \%; n survey $2017=380=100 \%$; n survey $2016=193=100 \%$; survey $2015=779=100 \%$

Source: own study

obtained in the research carried out in the rural-urban community, where this share amounted to $51.3 \%$ (survey of 2016), as well as in the urban community - 60.5\% (survey of 2015). This concerns noteworthy differences between the social reality in rural and urban areas, which is the prerequisite for further research.

Another issue worth highlighting in the structure of domestic violence in the types of areas described above, is the ranking of other forms of violence according to their incidence in the surveyed populations. While in rural areas the second most frequent form of violence was neglect (21.1\%), in other areas it ranked fourth (in the urban-rural community $-13.5 \%$, in the urban community - $22.3 \%$ ), being surpassed by physical violence (20.7\%) and economic violence (19.2\%) in the urban-rural community and by economic violence (29.3\%) and physical violence (25.4\%) in the urban community. Further in-depth research will allow determination about how regular the observed differences occur.

The collected empirical material allows for an even more detailed view of the phenomenon of domestic violence in terms of its forms:

\section{Psychological violence}

1. 1. In the communities under study this relatively most often took the form of harmful criticism from one of the family members (the 2017 study in a rural 
community - 25.6\%; the 2016 study in the urbanrural community $-31.6 \%$; the 2015 study in an urban community - 45.1\%). Similar to the incidence of this act of violence, the type of area determined its frequency; reported previous experience of harmful criticism were similar in all areas.

1. 2. The second most frequent type of psychological violence are offensive comments and vulgar terms. In the rural community (2017 survey), 21.6\% experienced them, in the urban-rural community $-27 \%$, and in the city $-34.7 \%$.

1. 3. In the rural community, $19.2 \%$ of respondents felt excessively and/or wrongly blamed in their home environment. In the urban-rural community, the number reached $27 \%$, and in the urban community $-40 \%$.

1. 4. Least frequent were cases of humiliation, persistent mockery or ridicule. This type of violence was experienced by $14 \%$ of respondents from the rural community, $14.5 \%$ in the urban-rural community and $25.7 \%$ in the urban community.

1. 5. Forcing submission by shouting is an indicator used only in the 2017 survey. $19.7 \%$ of respondents declared experiencing this act of psychological violence.

1. 6. Ridiculing interviewees by members of their families. This type of violence was experienced by $14 \%$ of respondents from the rural community, $14.5 \%$ in the urban-rural community and $25.7 \%$ in the urban community.

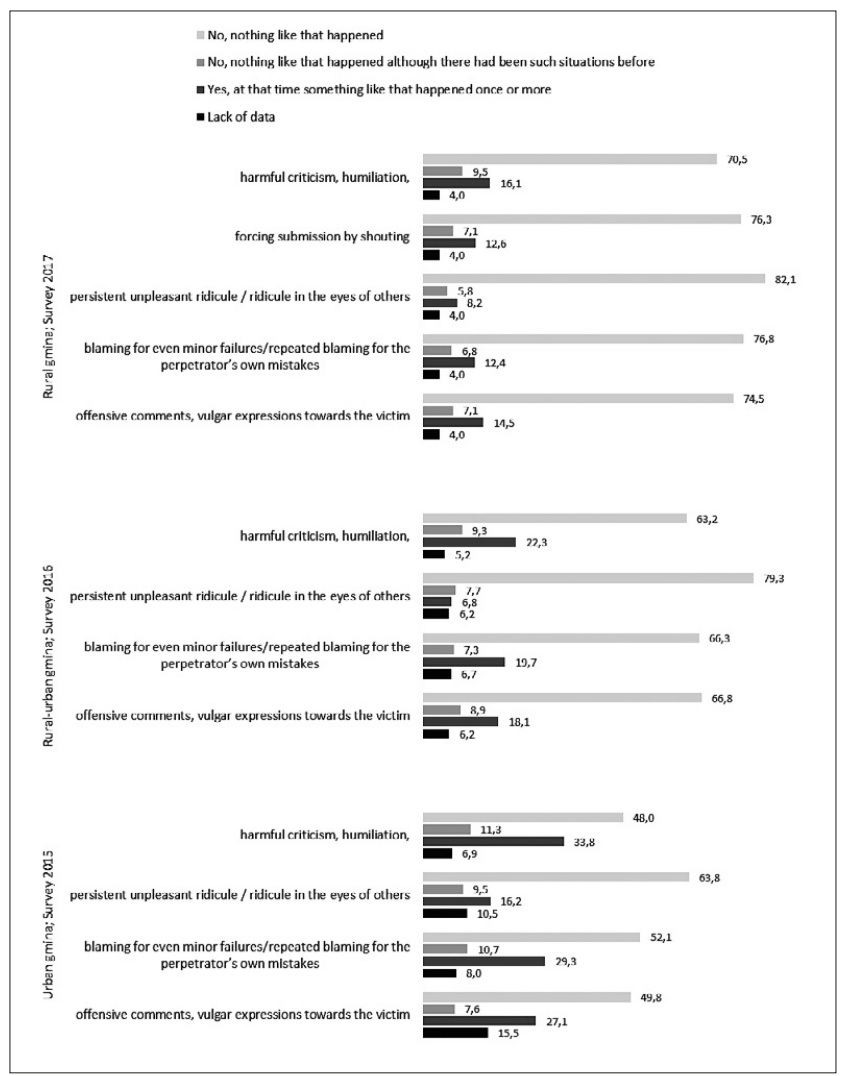

Figure 3. Scale of acts of domestic psychological violence experienced by schoolchildren and youths in three types of communities: rural, urban-rural and urban, according to conducted surveys

Data expressed in \%; $n$ survey $2017=380=100 \%$; $n$ survey $2016=193=100 \%$; n survey $2015=779=100 \%$

Source: Own study

\section{Physical violence}

2.1. Acts of physical violence expressed in the form of single or repeated slapping with the hand and/or kicking, etc., were experienced by $11.3 \%$ of respondents from the rural community (2017 survey), in the urban-rural community it was $19.7 \%$ (2016 survey), while in the urban community - $24.2 \%$ (2015 survey).

2.2. Beating with a tool that does not leave distinct, permanent marks on the body was experienced by $1.8 \%$ of respondents from the rural community (2017), $4.6 \%$ from the urban-rural community (2016), and $8.4 \%$ from the urban community (2015).

2.3. Beating that leaves distinct bruises or wounds was the experience of $2.1 \%$ of respondents from the rural community (2017), 5.7\% from the urban-rural community (2016), in the urban community $-7.4 \%$ (2015)

2.4. Jerking and/or stabbing or pushing, etc., e.g. to hasten the victim, are an indicator used only in the 2017 survey. $9.7 \%$ of respondents declared experiencing this act of psychological violence.

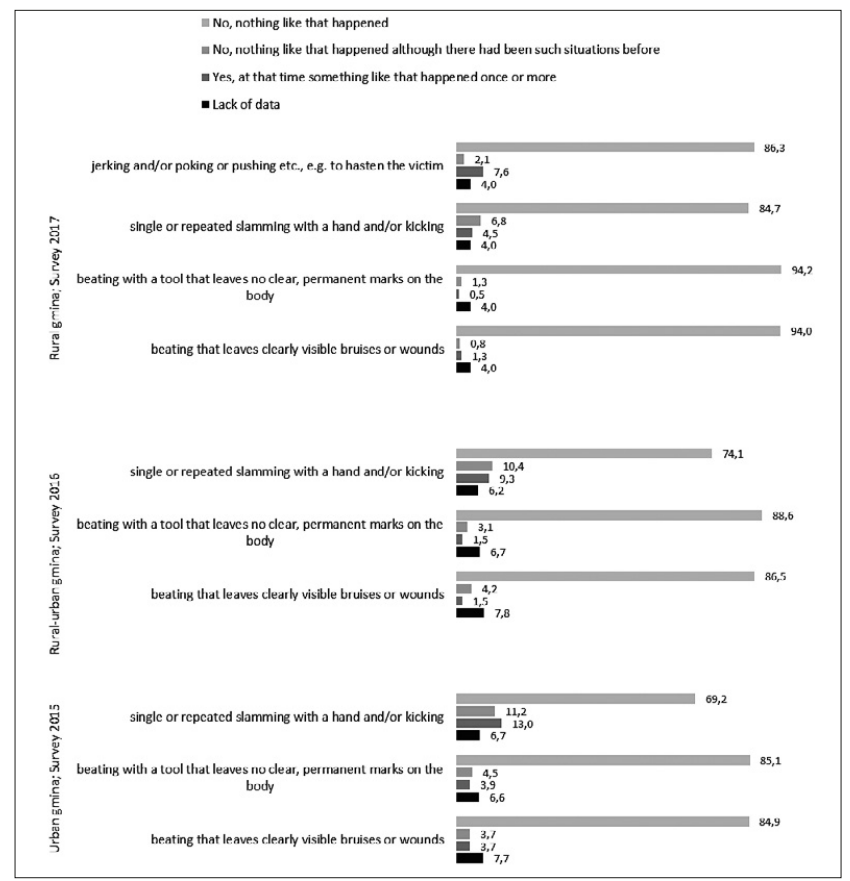

Figure 5. Scale of acts of domestic physical violence experienced by schoolchildren and youth in three community types: rural, urban-rural and urban, according to conducted surveys.

Data expressed in \%; n survey $2017=380=100 \%$; n survey $2016=193=100 \%$; n survey $2015=779=100 \%$

Źródło: badanie własne

\section{Neglect}

3.1. The number of respondents who experienced underestimation of their ill-health or failure to provide care in case of illness amounted to $10.2 \%$ in the rural community (2017), $13.5 \%$, in the urbanrural community a (2016) and $20.1 \%$ in the urban community (2015).

3.2. $1.3 \%$ respondents in the rural community (2017), $2.6 \%$ in the urban-rural community (2016) and $4.7 \%$ in the urban community (2015) experienced unjustified deprivation/restriction of food and/or drink (2017). 
3.3. Failure to provide necessary medical assistance was the experience of $2.6 \%$ respondents in the rural community (2017), 3.1\% in the urban-rural community (2016) and 5.1\% in the urban community (2015).

3.4. The indicator representing the lack of concern for problems and/or ignoring feelings/trivialising emotions was used in 2017 only, and the survey revealed that $16.3 \%$ of respondents encountered that form of domestic violence.

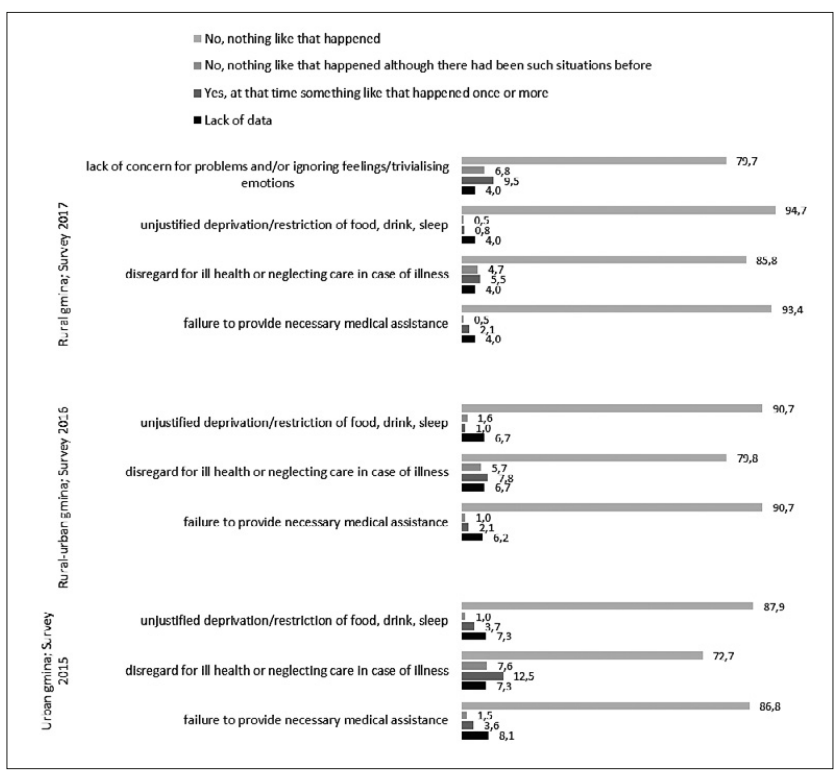

Figure 6. Scale of acts of domestic neglect experienced by school children and young people in three types of communities: rural, urban-rural and urban, according to conducted surveys.

Data expressed in \%; n survey $2017=380=100 \%$; n survey $2016=193=100 \%$; n survey $2015=779=100 \%$

Source: own study

\section{Economic violence}

4.1. $9.5 \%$ of respondents from the rural community (2017), $14 \%$ from the urban-rural community (2016) and $23.1 \%$ from the urban community (2015) reported disproportionate and persistent control of expenditure.

4.2. Refusal to pay/provide for reasonable needs by household members was experienced by $4.3 \%$ of respondents from the rural community (2017), by $9.3 \%$ from the urban-rural community (2016) and by $13.6 \%$ of respondents from the urban community (2015).

4.3. $1.9 \%$ respondents from the rural community (2017), $8.3 \%$ from the urban-rural community (2016) and $6.0 \%$ from the urban community (2015) reported that they had been deprived of/coerced into handing over their money.

\section{Sexual assault}

5.1. The collected empirical material revealed that $2.1 \%$ respondents from the rural community (2017 survey), $2 \%$ from the urban-rural community (2016 survey) and $3.1 \%$ from the urban community (2015 survey) reported experiencing unpleasant and unwanted sexual remarks.

5.2. $0.8 \%$ of respondents from the rural community (2017), $2.6 \%$ from the urban-rural community (2016) and $4.0 \%$ from the urban community (2015) experienced inappropriate touching places of their body parts.

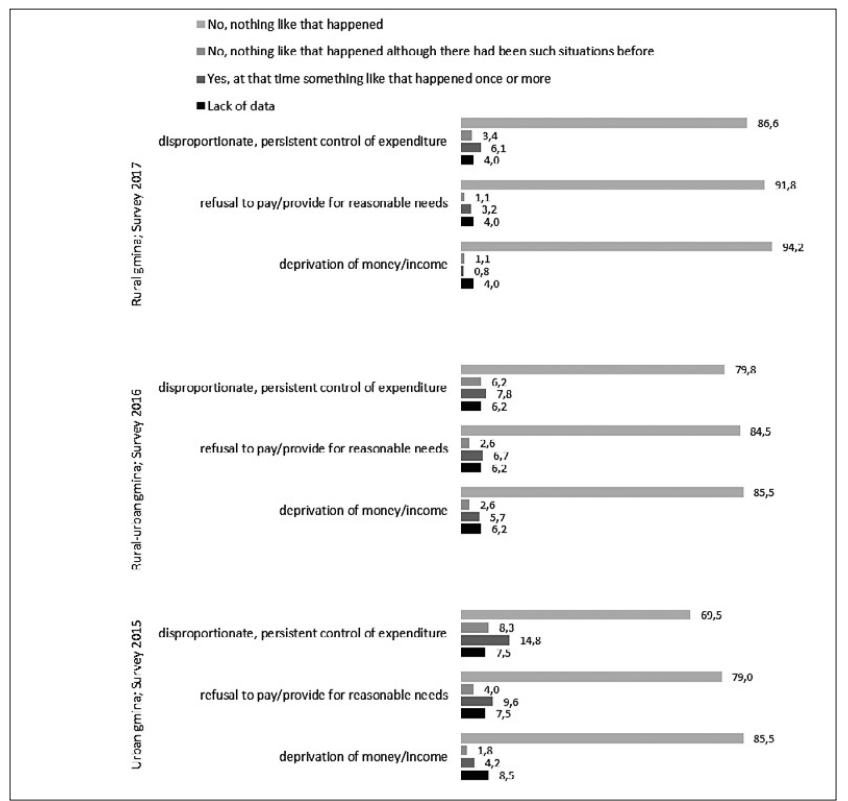

Figure 7. Scale of acts of domestic economical violence experienced by schoolchildren and youths in three community types: rural, urban-rural and urban, according to conducted surveys

Data expressed in \%; n survey $2017=380=100 \%$; n survey $2016=193=100 \%$; $n$ survey $2015=779=100 \%$

Source: own study

5.3. The most serious act of domestic sexual violence, i.e. sexual abuse, i.e. inappropriate, unacceptable sexual behaviour, was experienced by $0.8 \%$ of respondents from the rural community (2017 survey, the reported incidents had taken place earlier than the 6 months preceding the survey), and $1.9 \%$ of respondents from the urban community (2015). In the 2016 survey conducted in the urban-rural community, no such cases were revealed.

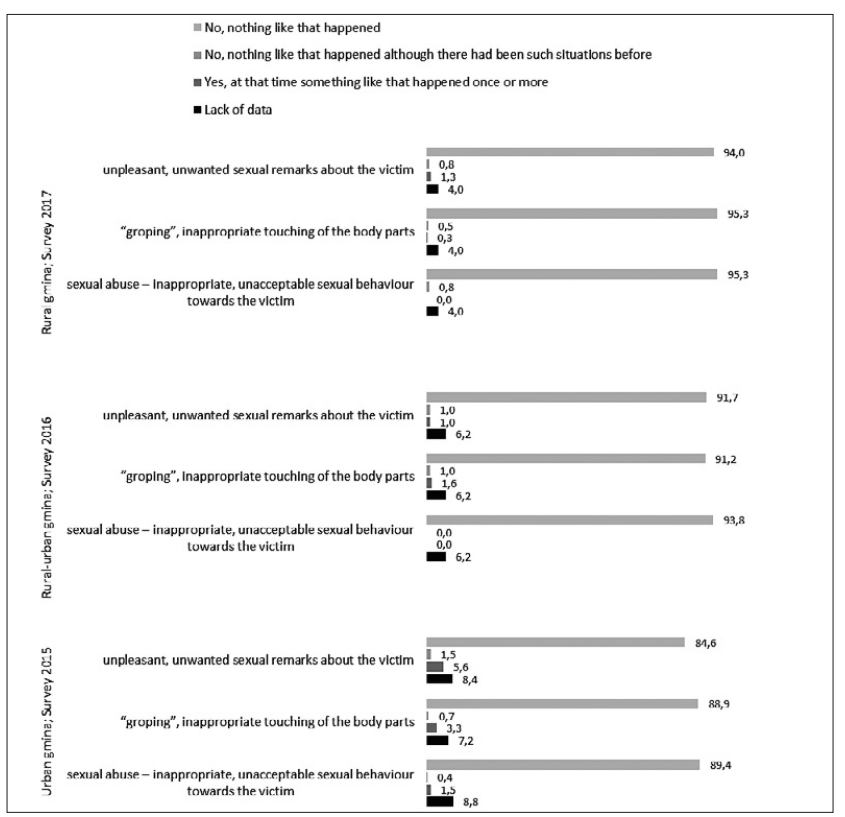

Figure 8. Scale of acts of domestic sexual assault experienced by schoolchildren and youths in three community types: rural, urban-rural and city, according to conducted surveys

Data expressed in \%; n survey $2017=380=100 \%$; n survey $2016=193=100 \%$; survey $2015=779=100 \%$ Source: own study 


\section{DISCUSSION}

Domestic violence is considered to be a threat to the existing system of values, a manifestation of breaking of the social norms and a symptom of social pathology on a national and global scale $[14,15,16]$. This vital issue has been within the scope of social and other studies in Poland for over 20 years, and interest in it is growing. In Poland initially, only parts of larger research projects were devoted to domestic violence, the most frequently referred to are the surveys of women conducted by the CBOS (Centre for Public Opinion Research) titled "Women '93" - on a nationwide representative random sample of adult women $(\mathrm{N}=1,087)$ and "Women ' 96 " - on a nationwide representative random sample of adult women $(\mathrm{N}=1,101)$, which also explored the problem of domestic violence, as well as a study of domestic violence towards children realized by CBOS in 2008 under the title: Social consent to beating children [17]. Gradually, more research began to appear that focused on various forms of family violence inflicted on (or by) different social groups, such as women, seniors or dependents, including children and adolescents. A milestone in the Polish research on the scale of domestic violence against children and teenagers was the Abused Children in Poland report published by the Ministry of Labour and Social Policy in 2008 [18]. According to the surveys presented in the report, every fifth Pole was convinced that violence affected half of the Polish families. Also, $15 \%$ of Poles with children up to the age of 18 had used violence against them at least once, $12 \%$ more than once, and $1 \%$ repeatedly.

The victimization of children and adolescents, including domestic violence, was an important subject of the 2013 National diagnosis of the problem of violence against children [19]. The studies showed that $71 \%$ of teenagers aged $11-17$ have experienced at least one form of violence in various situations, including the family environment.

Based on data from the Police Headquarters, the authors of the latest report on violence against children announced that the number of cases of domestic violence against children in Poland is decreasing - from 56.5 thousand in 2006 to 14.2 thousand in 2016. The proportion of children in the total number of victims of domestic violence is also declining from $36 \%$ in 2006 to $15 \%$ in 2016 [20]. However, these are official data, in the light of which the scale of domestic violence is usually smaller than is shown in sociological studies conducted on primary data. A significantly higher incidence of domestic violence is revealed by research carried out in 2014 under the project "Diagnosis and comparison of the incidence of domestic violence and assessment of the effectiveness of actions taken to counter domestic violence". According to the project, $47.1 \%$ of respondents declared knowledge of cases of domestic violence against children. The cases most often reported were of negligence (30.6\%), mental violence (26.4\%) and physical violence $(25.7 \%)$, while sexual violence was disclosed the least frequently $-4.2 \%$. In addition, $32 \%$ of teenagers knew at least one of their peers who experiences domestic violence [21]. However, these studies do not show the scale of violence against children, but only the scale of knowledge about such acts. It is difficult to deduce the scale of the phenomenon from the reported knowledge of child abuse in the domestic environment because some acts of violence are difficult to recognize (especially psychological violence). Surveys, from which this paper stems, shows that domestic violence affects $48.2 \%$ of schoolchildren and youths living in rural areas, $51.8 \%$ in urban-rural areas and $65.5 \%$ in urban areas, with psychological violence being the most widespread and neglect being reported less frequently. This does not indicate the superior value of one study over another, but only the different findings of both studies.

Domestic violence is usually investigated in Poland using surveys based on national samples of respondents. The researchers usually use official data, which may give a false picture of the phenomenon or its uncontrolled deformations. Therefore, the idea of conducting research in which empirical material consists of reports of respondents' personal experience (with the utmost caution against their secondary victimization) of persons belonging to specific social groups (e.g. violence against women - among women; violence against seniors - among seniors; violence against children - among children) seems justified, because the cross-sectional research, even if conducted on large samples representative for the whole population, may distort the picture of the phenomenon.

Another issue that is worth emphasizing, are the substantial differences between the types of population in rural, urbanrural and urban areas, which are manifested by the varying incidence of domestic violence experienced by schoolchildren and youths. This topic is practically ignored by researchers dealing with the phenomenon of domestic violence in Poland. It is also rarely addressed by studies in other countries where some researchers take into account the dichotomy of rural and urban areas, looking for dependencies in this respect. For example, studies by S. Walby and J. Allen show that up to a quarter of the victims of domestic violence live in rural areas, the remainder live in cities, half of whom in city centres and a quarter in suburban areas. It should be emphasized, however, that those researchers have presented data relating to the total population of the specified areas [22]. W. A. Walsh, and M. J. Mattingly, in turn, focus on the problem of domestic violence against children taking into consideration the rural-urban dichotomy. According to their findings, children living in cities (45\%) are slightly more likely to experience domestic violence than those in rural areas $(40 \%)[9,23]$.

\section{CONCLUSIONS}

- Depending on the type of area subject to the survey, the exposure to domestic violence experienced by schoolchildren and youths varies in scale (in the rural community $-48.2 \%$, i.e. $1-\alpha=0.95$ confidence interval: $43.2 \%-53.2 \%$ of the population; in the urban-rural community $-51.8 \%$, i.e. $1-\alpha=0.95$ confidence interval: $45.8 \%-59.8 \%$ of the population; in the urban community $-65.5 \%$, i.e. $1-\alpha=0.95$ confidence interval: $62.0 \%-69.0 \%$ of the population).

- Most frequently, respondents were exposed to a single form of domestic violence (rural community - 19.5\%, urbanrural community - $22.3 \%$, urban community - 23.7\%).

- The experience of 3 or more types of domestic violence indicates an atmosphere of concentrated violence in the family. Depending on the area, such a situation affects from $13.6 \%$ (the rural community), through $11.9 \%$ (urban-rural community) to $23.8 \%$ of survey participants living in a city.

- Simultaneous exposure to all 5 forms of domestic violence (psychological, physical, economic, sexual violence and 
neglect) is experienced from $0.5 \%$ of population in the rural community to $1 \%$ in the urban-rural community and $3,3 \%$ in the city.

- In the experience of schoolchildren and adolescents, psychological violence is predominant.

- The incidence of individual forms of domestic violence varies, depending on the type of area:

1. Psychological violence: rural areas $-42.4 \%$, urban-rural areas $-51.3 \%$, urban areas $-60.5 \%$.

2. Neglect: rural areas $-21.1 \%$, urban-rural areas $-13.5 \%$, urban areas $-22.3 \%$.

3. Physical violence: rural areas $-17.1 \%$, urban-rural areas $-20.7 \%$, urban areas $-29.4 \%$.

4. Economic violence: rural areas - $12.6 \%$, urban-rural areas $-19.2 \%$, urban areas $-29.3 \%$.

5. Sexual violence: rural areas $-3.2 \%$, urban-rural areas $-3.6 \%$, urban areas $-8.1 \%$.

- The incidence of forms of domestic violence against school children and adolescents: psychological, physical and economic, allow hypotheses for further research on the relationship between the incidence of domestic violence and the type of area: in urban-rural areas the aforementioned forms of domestic violence occur on a larger scale than in rural areas, and in on smaller scale than in urban areas.

\section{REFERENCES}

1. Widera-Wysoczańska A. Familly violence mechanizms. From one generation to another. Warszawa: Difin S.A.; 2010.

2. Gumowska I. Scale and structure of domestic violence. In: Domestic violence - an interdisciplinary approach. Kraków: Impuls; 2017. p. 161-81.

3. Lloyd M. Domestic Violence and Education: Examining the Impact of Domestic Violence on Young Children, Children, and Young People and the Potential Role of Schools. Front Psychol. 2018; 9. Available from: https://www.ncbi.nlm.nih.gov/pmc/articles/PMC6243007/ DOI: 10.3389/fpsyg.2018.02094

4. Consultation on Child Abuse Prevention (1999: Geneva S, Team WHOV and IP, Research GF for H. Report of the Consultation on Child Abuse Prevention, 29-31 March 1999, WHO,Geneva: World Health Organization; 1999 [cited 2018 Dec 10]. Report No.: WHO/HSC/ PVI/99.1. Available from: http://apps.who.int/iris/handle/10665/65900

5. Act of 29 July $2005 \mathrm{r}$. on counteracting domestic violence, Art. 2, point 2. Journal of Laws No 180, item 1493; 2005.

6. Helios J, Jedlecka W. Violence against children. In: Contemporary faces of violence Selected issues. Wrocław: Uniwersytet Wrocławski; 2017. p. 77-122. Available from: http://www.bibliotekacyfrowa.pl/ publication/85031

7. Hornor G. Domestic Violence and Children. J Pediatr Health Care. 2005; 19(4): 206-12. Available from: http://www.sciencedirect.com/science/ article/pii/S0891524505000891 DOI: 10.1016/j.pedhc.2005.02.002

8. Stalford H, Baker H, Beveridge F. Children and Domestic Violence in Rural Areas: A child-focused assessment of service provision. Save the Children. London; 2003 [cited 2018 Dec 10]. Available from: http://
www.equation.org.uk/wp-content/uploads/2012/12/Children-anddomestic-violence-in-Rural-Communities.pdf

9. Walsh WA, Mittingly MJ. Understanding child abuse in rural and urban America: risk factors and maltreatment substantiation. ResearchGate. [cited 2018 Dec 8]. Available from: https://www.researchgate.net/ publication/254721677_Understanding_child_abuse_in_rural_and_ urban_America_risk_factors_and_maltreatment_substantiation

10. Ajah LO, Iyoke CA, Nkwo PO, Nwakoby B, Ezeonu P. Comparison of domestic violence against women in urban versus rural areas of southeast Nigeria. Inter J Women's Health. 2014. Available from: https:// www.dovepress.com/comparison-of-domestic-violence-againstwomen-in-urban-versus-rural-ar-peer-reviewed-article-IJWH DOI: 10.2147/IJWH.S70706

11. Peek-Asa C, Wallis A, Harland K, Beyer K, Dickey P, Saftlas A. Rural Disparity in Domestic Violence Prevalence and Access to Resources. J Womens Health. 2011; 20(11): 1743-9. Available from: https://www.ncbi. nlm.nih.gov/pmc/articles/PMC3216064/DOI: 10.1089/jwh.2011.2891

12. Terelak A, Kołodziejczak S, Klepajczuk B. Integrated action towards family violence. Manual of creating and coordinating interdisciplinary teams. Szczecin: Marshall Office of West Pomerania Woivodeship; 2010.

13. Jarosz E, Nowak A. Children as victims of domestic violence. Report of the ombudsman. Warszawa: Ombudsman; 2012 [cited 2018 Dec 12]. Available from: http://brpd.gov.pl/sites/default/files/dzieci_ofiary_ przemocy_w_rodzinie.pdf

14. Moody G, Cannings-John R, Hood K, Kemp A, Robling M. Establishing the international prevalence of self-reported child maltreatment: a systematic review by maltreatment type and gender. BMC Public Health. 2018; 18. Available from: https://www.ncbi.nlm.nih.gov/pmc/ articles/PMC6180456/ DOI: 10.1186/s12889-018-6044-y

15. Arie S. WHO takes up issue of child abuse. BMJ. 2005; 331(7509): 129. Available from: https://www.ncbi.nlm.nih.gov/pmc/articles/ PMC558693/

16. Holt S, Buckley H, Whelan S. The impact of exposure to domestic violence on children and young people: A review of the literature. Child Abuse Neg. 2008; 32(8): 797-810. Available from: http://www. sciencedirect.com/science/article/pii/S0145213408001348 DOI: 10.1016/j.chiabu.2008.02.004

17. Social consent to beating children. Warszawa: CBOS; 2008. Available from: https://www.cbos.pl/SPISKOM.POL/2008/K_106_08.PDF

18. Abused Children in Poland. Warszawa: Ministry of Labour and Social Politics; 2008. Available from: https://www.malopolska.uw.gov.pl/doc/ Krzywdzenie_dziec_w_Polsce_Raport.pdf

19. Violence against children in Poland. Diagnosis and recommendations. Warszawa: Nobody's Children Foundation; 2013. Available from: http:// www.umwd.dolnyslask.pl/fileadmin/user_upload/Zdrowie/PiRPU/ Przemoc_Diagnoza_i_rekomendacje_FDN.pdf

20. Children count 2017. Report on the threats to safety and development of children in Poland. 'A child who is hurt. Theory, research, practice'. Warszawa: Nobody's Children Foundation; 2017. Report No.: vol 16, No 1.

21. Miedzik M, Godlewska-Szurkowa J, Rutkowski J. Comparative research and diagnosis of the scale of occurrence of domestic violence among adults and children, divided into individual forms of violence along with a description of the characteristics of victims of violence and perpetrators. Partial report. Warszawa: WYG PSDB Sp. z o. o; 2014.

22. Walby S, Allen J. Domestic violence, sexual assault and stalking: Findings from the British Crime Survey. London: Development and Statistics Directorate; 2004 Mar.

23. Mittingly MJ, Walsh WA. Rural Families with a Child Abuse Report are More Likely Headed by a Single Parent and Endure Economic and Family Stress. [cited 2018 Dec 8]. Available from: http://unh.edu/ccrc/ pdf/CV216.pdf

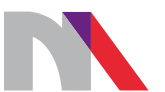

Ministry of Science and Higher Education

Republic of Poland

Generation of the DOI (Digital Object Identifier) - task financed under the agreement No. 618/P-DUN/2019 by the Minister of Science and Higher Education 